\title{
Phylogenetic and Biochemical Characterization of a New Halo-Thermotolerant, Biofilm-Forming Bacillus from Saline Lake of Iran
}

\author{
AZAM SAFARY ${ }^{1}$, REZVAN MONIRI $^{2,1 *}$, SEYYED MEHDI MIRHASHEMI ${ }^{3}$, HOSSEIN NIKZAD $^{1}$ \\ AND MOSTAFA AKBARZADEH KHIAVI ${ }^{4}$
}

\author{
${ }^{1}$ Anatomical Sciences Research Center, Kashan University of Medical Sciences \\ Kashan, Iran \\ ${ }^{2}$ Department of Microbiology and Immunology, Faculty of Medicine \\ Kashan University of Medical Sciences, Kashan, Iran \\ ${ }^{3}$ Research Center for Biochemistry and Nutrition in Metabolic Diseases \\ Kashan University of Medical Sciences, Kashan, Iran \\ ${ }^{4}$ Department of Molecular Biology, Faculty of Basic Sciences, Ahar Branch \\ Islamic Azad University, Ahar, Iran
}

Submitted 12 February 2013, revised 12 June 2013, accepted 16 November 2013

\begin{abstract}
In this study, five halotolerant Bacillus isolates from Aran-Bidgol Saline Lake in Iran were identified from saline environments. Screening of the bacteria led to the identification of a unique halo-thermotolerant Bacillus. On the basis of genetic and phenotypic data, this isolate was closely related to Bacillus licheniformis. But isolated Bacillus can be distinguished from B. licheniformis by salt tolerance, $16 \mathrm{~S}$ rDNA sequence and some different physicochemical properties. Thus, suggested that the isolate was not the known Bacillus. Optical density analysis indicated strong biofilm formation for this strain. Also this isolate exhibited average tolerance to $1-25 \mathrm{mM}$ concentrations of zinc and was sensitive to all concentrations of nickel. In biosurfactant production assay, this Bacillus exhibited the high activity for semi-quantitative oil displacement test $\left(3.14 \pm 0.02 \mathrm{~cm}^{2}\right)$ and evaluated positive for drop-collapse test and hemolytic activity. Moreover, amylase, protease and DNase enzymes produced in presence of $10-20 \%$ salt of medium. Therefore, identified Bacillus could supply potential microbial materials for bioremediation purposes and biotechnological applications.
\end{abstract}

Ke y w ord s: biofilm formation, halo-thermotolerant Bacillus, phylogenetic analysis, Saline Lake

\section{Introduction}

The properties of saline and hypersaline habitats on earth are reflected in the great diversity within the microbial communities adapted to life under the prevailing conditions (Oren, 2002a). The aspects that attracted the attention of researchers were mainly those related to their physiological adaptation to highly saline concentrations and their ecology (Ghozlan et al., 2006; Ventosa et al., 1998a; 1998b). Recently, increasing interest, in microorganisms from hypersaline environments led to the discovery of several new bacterial species and genera (Yildiz et al., 2011). Besides their important role in the ecology of hypersaline environments, these prokaryotes, could be used in a multitude of potential applications in various fields of biotechnology (Coronado et al., 2000).
They are a good quality source for compatible solutes that can be used as salt antagonists, stabilizers of biomolecules and whole cells, or stress-protective agents (Margesin and Schinner, 2001). Other useful bio-substances are exoenzymes, such as new isomerases and hydrolases that are active and stable at high salt concentrations. In addition, biopolymers such as biosurfactants and exopolysaccharides are of interest in enhanced oil recovery processes, degradation of industrial residues and toxic chemicals that can pollute hypersaline habitats has also been claimed (Coronado et al., 2000; Margesin and Schinner, 2001; Ventosa et al., 1998b).

On the other hand, in their natural environment, some halophilic bacteria occur in microbial aggregates as biofilm communities. It seems that the biofilm structure allows the attachment to various substrates and the

\footnotetext{
* Corresponding author: R. Moniri, Kashan University of Medical Sciences, Ghotbe Ravandi Avenue, P.O Box 87155-111, Kashan, Iran; phone: (+98) 361555 0021-25; fax: (+98) 361555 1112; e-mail: moniri@kaums.ac.ir
} 
survival of cells by their interactions with ions such as heavy metals (Davey and Otoole, 2000; Maugeri et al., 2010; Poli et al., 2010). Thus, detoxifying ability of these microorganisms can be manipulated for bioremediation of heavy metals in wastewater systems (Kamika and Momba, 2011). Therefore extreme environments can offer novel microbial biodiversity that produces varied and promising useful bio-substances for biotechnological applications (Llamas et al., 2010; Mata et al., 2006; Nichols et al., 2005). Aran-Bidgol Saline Lake in the central part of Iran is a hypersaline environment that similarly to other hypersaline ecosystems is subjected to drastic physicochemical conditions including high salinity, high radiation and strong changes in temperatures and dryness which make it an applicable study target for microbiologists.

In this study, we report the determination of phylogenetic properties, phenotypic features, physiologi$\mathrm{cal}$ and biochemical characteristics of a new halo-thermotolerant Bacillus from the Aran-Bidgol Saline Lake of Iran with a practical perspective on biotechnology. Also, important properties of this isolate such as biofilm formation ability, biosurfactant production, extracellular hydrolytic activates, nickel and zinc resistance were evaluated.

\section{Experimental}

Material and Methods

Physicochemical analysis of the samples. Samples for isolation of bacteria were collected $10 \mathrm{~cm}$ below the water surface of the lake in June 2011. Ion content of the water samples were measured according to standard methods (Lenore et al., 1989). $\mathrm{Na}^{+}, \mathrm{K}^{+}$and $\mathrm{Ca}^{2+}$ were quantified by flame spectrophotometer (Genway, Uk), $\mathrm{Mg}^{2+}$ was quantified by atomic absorption spectrophotometer (Analytik Jena, Germany). PH and temperature were determined in situ.

Enrichment, bacterial isolation and culture conditions. Enrichment procedures were performed in medium including brine sample enriched with $2.5 \mathrm{~g} / \mathrm{l}$ yeast extract (Difco) and $5 \mathrm{~g} / \mathrm{l}$ tryptone (Difco). One hundred $\mathrm{ml}$ of each enriched medium was placed into $250 \mathrm{ml}$ flasks. Cultures were incubated at $35^{\circ} \mathrm{C}$ and in an orbital shaker, at $150 \mathrm{rpm}$, during 3-7 days. After 4 days of incubation, the enrichment culture were spread on a saline nutrient agar plates, with a final concentration of $10 \%$ sea salt, containing (per liter): $\mathrm{NaCl}$, 250 g; $\mathrm{MgCl}_{2} 6 \mathrm{H}_{2} \mathrm{O}, 13 \mathrm{~g} ; \mathrm{MgSO}_{4} 7 \mathrm{H}_{2} \mathrm{O}, 20 \mathrm{~g} ; \mathrm{KCl}, 4 \mathrm{~g}$; $\mathrm{CaCl}_{2} 2 \mathrm{H}_{2} \mathrm{O}, 1 \mathrm{~g} ; \mathrm{NaHCO}_{3}, 0.2 \mathrm{~g}$ for moderately halophilic bacteria and $20 \%(\mathrm{w} / \mathrm{v})$ for extremely halophilic microorganisms (Rohban et al., 2009), supplemented with $2.5 \%$ yeast extract and $5 \%$ tryptone, solidified with
10-12 g/l agar. Different colonies were picked and passaged several times to obtain pure cultures. Microbial cultures were stored at $-80^{\circ} \mathrm{C}$ in the isolation medium supplemented with $10 \%$ glycerol.

Morphological, physiological and biochemical tests. All assay media for characteristics of the isolates were supplemented with $10 \%$ and $20 \%$ sea salt. Physiological and biochemical tests were performed as recommended by Smibert and Krieg (1994). Hydrolytic enzymes activities of isolates were screened qualitatively according to Rohban et al. (2009). Cultures were tested in triplicate and compared with negative and positive control. For assays of salt tolerance, cultures were incubated in nutrient broth containing $0,2,5,7$ and $10 \%(\mathrm{w} / \mathrm{v}) \mathrm{NaCl}$. Duplicate culture tubes containing $6 \mathrm{ml}$ medium were inoculated with a loopful of $24 \mathrm{~h}$ culture grown in nutrient broth at $30^{\circ} \mathrm{C}$. The inoculated tubes were incubated at $37^{\circ} \mathrm{C}$ and monitored for growth at 2 day.

$16 \mathrm{~S}$ rDNA analysis. The genomic DNA of isolates was extracted by QIAamp DNA Mini Kit (Qiagene, Germany) according to the manufacturer's instructions. The 16S rDNA gene was amplified by using primers FD1 (5'-CGAATTCGTCGACAACAGAGTTTGATCCTGGCTCAG-3') and RP1 (5'-CCCGGGATC CAAGCTTACGGTTACCTTGTTACGACTT-3') (Weisburg et al., 1991). PCR was performed in a thermal cycler (Bioneer, South Korea). The reaction mix included smarTaq DNA polymerase (Cinnagen, Iran) $0.25 \mu \mathrm{l}$, $0.5 \mu$ l of each primer, dNTP $(10 \mathrm{mM}) 0.5 \mu \mathrm{l}$, PCR buffer (10X) $2.5 \mu \mathrm{l}, \mathrm{MgCl}_{2}(50 \mathrm{mM}) 0.75 \mu \mathrm{l}$, template DNA $2 \mu \mathrm{l}$, and $\mathrm{dH}_{2} \mathrm{O} 18 \mu \mathrm{l}$, in a final volume of $25 \mu \mathrm{l}$. The PCR amplification was performed using the following program: initial denaturation at $94^{\circ} \mathrm{C}$ for $3 \mathrm{~min}$, followed by 30 cycles of denaturation at $94^{\circ} \mathrm{C}$ for $1 \mathrm{~min}$, primer annealing at $61^{\circ} \mathrm{C}$ for $30 \mathrm{~s}$, and extension at $72^{\circ} \mathrm{C}$ for 2 min with final $10 \mathrm{~min}$ extension at $72^{\circ} \mathrm{C}$. PCR product was analyzed on $1 \%$ agarose gel stained with ethidium bromide $(0.5 \mu \mathrm{g} / \mathrm{ml})$ and visualized under ultra violet transillumination (Syngene InGenius, US). PCR products were sequenced using an automated sequencer (ABI system, 3730XL) by Macrogen Company in Korea. The phylogenetic relationship of the isolates were determined by comparing with the related sequences in the GenBank database by advanced BLAST searches from National Center for Biotechnology Information. Among the isolated strains, SL1 isolate, was selected for further identification based on its high salt and thermo tolerance, hydrolytic activity, biochemical properties and $16 \mathrm{~S}$ rDNA data

Phylogenetic tree of SL1 isolate. Phylogenetic tree analysis was performed by using the software package MEGA5 version (Tamura et al., 2011) after obtaining multiple alignments of data available from public databases using CLUSTAL W (Thompson et al., 1994). Pair 
wise evolutionary distances were computed using the correction method and clustering was performed using the neighbor-joining method (Saitou and Nei, 1987). Bootstrap analysis was used to evaluate the tree topology of the neighbor-joining data by performing 2,000 replicates (Zharkikh and $\mathrm{Li}, 1995)$.

Biofilm formation of SL1 isolate. Quantitative analysis of biofilm production was performed as described by Seno et al. (2005), with some modifications. Briefly, the isolate was grown in tryptic soy broth (TSB) with $10 \%$ and $20 \%(\mathrm{w} / \mathrm{v})$ sea salt. From each culture, $20 \mu \mathrm{l}$ samples and $180 \mu \mathrm{l}$ of TSB were dispensed in the wells of sterile 96-well flat-bottomed microtiter plate (BD Biosciences) and incubated at $35^{\circ} \mathrm{C}$ for $48 \mathrm{~h}$. The control wells contained only TSB medium. After $48 \mathrm{~h}$, wells were washed three times with distilled water, dried and fixed for $30 \mathrm{~min}$ at $80^{\circ} \mathrm{C}$. Adhered cells were stained with $0.5 \%$ crystal violet solution for $30 \mathrm{~min}$. The stain was washed out with distilled water. In order to quantify adhered cells, $220 \mu \mathrm{l}$ of ethanol-acetic acid (95: 5, $\mathrm{vol} / \mathrm{vol}$ ) was added to each well for $15 \mathrm{~min}$. Optical density (OD) of eluted stain was measured at $590 \mathrm{~nm}$ by using a microtiter plate reader (Awareness technology INC, U.S). Each assay was performed triplicate. As a control uninoculated medium was used. The strain with $A_{590}<0.5$, and $A_{590} \geq 0.5$ were defined as weak and strong biofilm formers, respectively.

Biosurfactant production of SL1 isolate. Examination of biosurfactant production and surface tension was performed by Drop-collapse, Oil displacement and hemolytic activity tests (Bodour et al., 2003; Morikawa et al., 1993). Briefly, the isolate was cultured in broth medium and incubated at $36^{\circ} \mathrm{C}$ for 3 days. Cell suspensions were centrifuged $(10,000 \mathrm{~g})$ and the cell-free supernatant was used for analysis. Drop-collapse test was performed in the polystyrene lid of a 96-microwell plate. Cultures were tested in triplicate. The broth medium alone was a negative drop-collapse control. In oil displacement test, $15 \mu$ l of crude oil were added on the surface of distilled water $(40 \mu \mathrm{l})$ in a Petri dish. Then, $10 \mu$ l of the medium supernatant were quietly put on the center of the oil film. The diameter and area of clear halo visualized under visible light were measured and calculated after 30 second. Also, the hemolytic activity of SL1 was screened on blood agar plates containing 5\% (v/v) human blood.

Effects of nickel $\left(\mathrm{Ni}^{+}\right)$and zinc $\left(\mathrm{Zn}^{+2}\right)$ on SL1 growth. Toxicity of nickel $\left(\mathrm{NiSO}_{4}\right)$ and zinc $\left(\mathrm{ZnCl}_{2}\right)$ determined by using methods of Hassen et al. (1998). Different concentrations of each metal prepared. The ranges of concentrations for heavy metals were 0,1 , $3,5,10,25,50,100,125$ and $150 \mathrm{mM}$. Ion solutions were prepared in tubes with a final volume of $10 \mathrm{ml}$ of nutrient broth (Merck, Germany). A metal-deficient Medium inoculated with the $200 \mu \mathrm{l}$ of micro- organism. A metal-supplemented media without the bacteria (abiotic control) were used as negative controls. After $24 \mathrm{~h}$ incubation, bacterial growth was measured (OD $600 \mathrm{~nm}$ ) (CE2021, U.K). Each assay was performed triplicate.

Nucleotide sequence accession numbers. The $16 \mathrm{~S}$ rDNA sequences have been submitted to GenBank with accession numbers: strain SL1 (JQ996502)

\section{Results}

Physicochemical analysis of the water samples. $\mathrm{Na}^{+}$, $\mathrm{K}^{+}, \mathrm{Ca}^{2+}$ and $\mathrm{Mg}^{2+}$ content of samples were $37500 \mathrm{ppm}$, $4500 \mathrm{ppm}, 2400 \mathrm{ppm}$ and $23741 \mathrm{ppm}$, respectively. The results showed that the water samples from the studied lake were saturated with $\mathrm{Na}^{+}$and contained high levels of $\mathrm{Mg}^{+2}$. The $\mathrm{pH}$ of samples was between 7.13-7.49 and average of temperature at the sampling sites was $42^{\circ} \mathrm{C}$.

Phenotypic characterizations of the isolates. The analysis of the isolates could be further identified them as part of a major Firmicutes group. The Firmicutes group related to the Bacillaceae family was represented by five strains. The results of phenotypic characterizations of isolates are shown in Table I. Among the isolates, SL1 grew well in wide range (up to $10 \%$ ) of $\mathrm{NaCl}$ concentrations and $20-55^{\circ} \mathrm{C}$ of temperature. Optimum growth in wide range of salt indicated that the $\mathrm{NaCl}$ is not required for growth of SL1; therefore the isolate was regarded as a halotolerant Bacillus. Also this isolate produced three important hydrolytic enzymes in presence of $10 \%$ and $20 \%$ sea salt.

Phylogenetic analysis. Phylogenetic analysis based on 16S rDNA gene sequence comparisons revealed that the isolates SL2 and SL4 resembled to Bacillus safensis by $98 \%$ and $99 \%$ respectively. There were a $99 \%$ similarity between the isolate SL3 and Bacillus pumilus and 99.5\% between the SL5 and Bacillus sonorensis. Also, the isolate SL1 fell within the branch encompassing members of the genus Bacillus and was related to Bacillus licheniformis with 97.0\% 16S rDNA gene sequence similarity (Fig. 1). But SL1 isolate can be distinguished from $B$. licheniformis by physicochemical properties, $16 \mathrm{~S}$ rDNA sequence and phylogenetic tree. Thus, suggested that the strain was not the known Bacillus and was tentatively named as Bacillus sp. SL1. This Bacillus considered as a unique microorganism for further study.

Biofilm formation and biosurfactant production of SL1 isolate. In Biofilm formation assay, optical density (OD) of eluted stain in $590 \mathrm{~nm}$ was $1.25 \pm 0.31$. This result indicated that the SL1 isolate have a strong $\left(\mathrm{OD}_{590} \geq 0.5\right)$ biofilm formation in present of $10 \%$ and $20 \%$ sea salt concentration. In semi-quantitative test for biosurfactant production the SL1 exhibited the high activity for oil displacement test toward Crude 
Table I

Phenotypic characterizations and biochemical properties of isolates

\begin{tabular}{|c|c|c|c|c|c|}
\hline $\begin{array}{c}\text { Phenotypic } \\
\text { Characterizations }\end{array}$ & SL1 & SL2 & SL3 & SL4 & SL5 \\
\hline Gram reaction & + & + & + & + & + \\
\hline Spore formation & + & + & + & + & + \\
\hline Mucoid Colony & + & - & - & + & - \\
\hline Motility & - & + & - & + & + \\
\hline Oxidase & + & + & + & + & + \\
\hline Catalase & + & + & + & + & + \\
\hline Voges-Proskauer test & + & + & + & + & + \\
\hline \multicolumn{6}{|l|}{ Acid from } \\
\hline D-Glucose & + & + & + & + & + \\
\hline D-Mannitol & + & + & + & + & + \\
\hline Lactose & + & + & + & + & + \\
\hline Sucrose & + & + & + & + & + \\
\hline Gas from glucose & - & - & - & - & - \\
\hline Utilization of Citrat & - & - & - & - & - \\
\hline \multicolumn{6}{|l|}{ Formation of } \\
\hline Indole & - & - & - & - & - \\
\hline $\mathrm{H}_{2} \mathrm{~S}$ & - & - & - & - & - \\
\hline $\mathrm{NaCl}$ required for growth & - & - & - & - & - \\
\hline \multicolumn{6}{|l|}{ Hydrolytic activity } \\
\hline Amylase & + & - & - & - & - \\
\hline Protease & + & + & + & + & + \\
\hline DNase & + & - & + & - & + \\
\hline \multicolumn{6}{|l|}{ Hemolytic Activity } \\
\hline$\alpha$ & + & - & - & - & - \\
\hline$\beta$ & - & + & + & + & - \\
\hline \multicolumn{6}{|l|}{ Growth in $\mathrm{NaCl}$} \\
\hline $2 \%$ & + & + & + & + & + \\
\hline $5 \%$ & + & + & + & + & - \\
\hline $7 \%$ & + & + & + & + & - \\
\hline $10 \%$ & + & $\mathrm{Nd}^{*}$ & - & $\mathrm{Nd}^{*}$ & - \\
\hline $12 \%$ & + & - & - & - & - \\
\hline \multicolumn{6}{|l|}{ Growth at } \\
\hline $5^{\circ} \mathrm{C}$ & - & - & - & - & - \\
\hline $10^{\circ} \mathrm{C}$ & - & + & + & + & - \\
\hline $30^{\circ} \mathrm{C}$ & + & + & + & + & + \\
\hline $40^{\circ} \mathrm{C}$ & + & + & + & + & + \\
\hline $50^{\circ} \mathrm{C}$ & + & + & - & + & + \\
\hline $55^{\circ} \mathrm{C}$ & + & - & - & - & + \\
\hline $65^{\circ} \mathrm{C}$ & - & - & - & - & - \\
\hline Optimum pH & 7.0 & 7.0 & 7.0 & 7.0 & 7.0 \\
\hline
\end{tabular}

* Non detectable

Oil $\left(3.14 \pm 0.02 \mathrm{~cm}^{2}\right)$ and clear haloes on blood agar plate. Also, this strain evaluated positive for drop-collapse test and emulsified crude oil in broth medium within $48 \mathrm{~h}$ of cultivation.
Zinc and nickel resistance of SL1 isolate. The ability of the SL1 to tolerate zinc and nickel was tested by tube method. The high concentrations of zinc in broth medium were effective on bacterial growth (Fig. 2). This strain exhibited average degree of tolerance to $1-25 \mathrm{mM}$ concentrations of zinc $\left(\mathrm{OD}_{600} \mathrm{~nm} 0.480-0.141\right)$ and could live in medium with more than $25 \mathrm{mM}$ zinc. On the other hand, nickel inhibited the growth of strain at very low concentrations. The lower optical density values revealed that the bacterial growth was affected due to the presence of metal in the growth medium (Fig. 2).

\section{Discussion}

Recent decades have seen a flow in studies on extreme environments including hypersaline ecosystems (Demergasso et al., 2004; Oren, 2002b). The hypersaline Lake Aran-Bidgol is located at an altitude of $800 \mathrm{~m}$ in an area with an arid to semiarid continental climate. It was formed by the deposition of halite sediments from an ancient sea in different geological periods (Makhdoumi-Kakhki et al., 2011). According to the results of physicochemical analysis, sodium and magnesium concentrations of water samples were a high level, similarly to thalassohaline systems content. In addition, several interfering factors such as season, temperature, moisture and depth of sampling site could affect the ion concentrations of lake.

New halophilic Bacillus species from Aran-Bidgol saline Lake have been previously described. Recently Bacillus iranensis isolated from saline mud of this lake by Bagheri et al. (2012). In the present study, among the isolated strains, SL1 isolate was selected for further identification for its high halo-thermo tolerance and ability to produce most important industrial enzymes in present of $10 \%$ and $20 \%$ sea salt. Since most industrial procedure are performed under specific physicochemical conditions which may not be definitively adjusted to the optimal points needed for the activity of the existing enzymes; therefore, it would be of great importance to have enzymes that exhibit best possible activities at various ranges of salt concentration, $\mathrm{pH}$ and temperature. It is interesting to note that combined hydrolytic activity was detected in many halophilic strains (Rohban et al., 2009). Thus, these organisms are an excellent source of such enzymes that may be active at extreme conditions (Gomes and Steiner, 2004).

As determined by phylogenetic analysis, the SL1 isolate was closely related to the Bacillus licheniformis. But, according to the $16 \mathrm{~S}$ rDNA sequencing and some physicochemical properties, SL1 was different from B. licheniformis that previously described. B. licheniformis is a Gram-positive, endospores forming and industrial organism that can be isolated from soils 


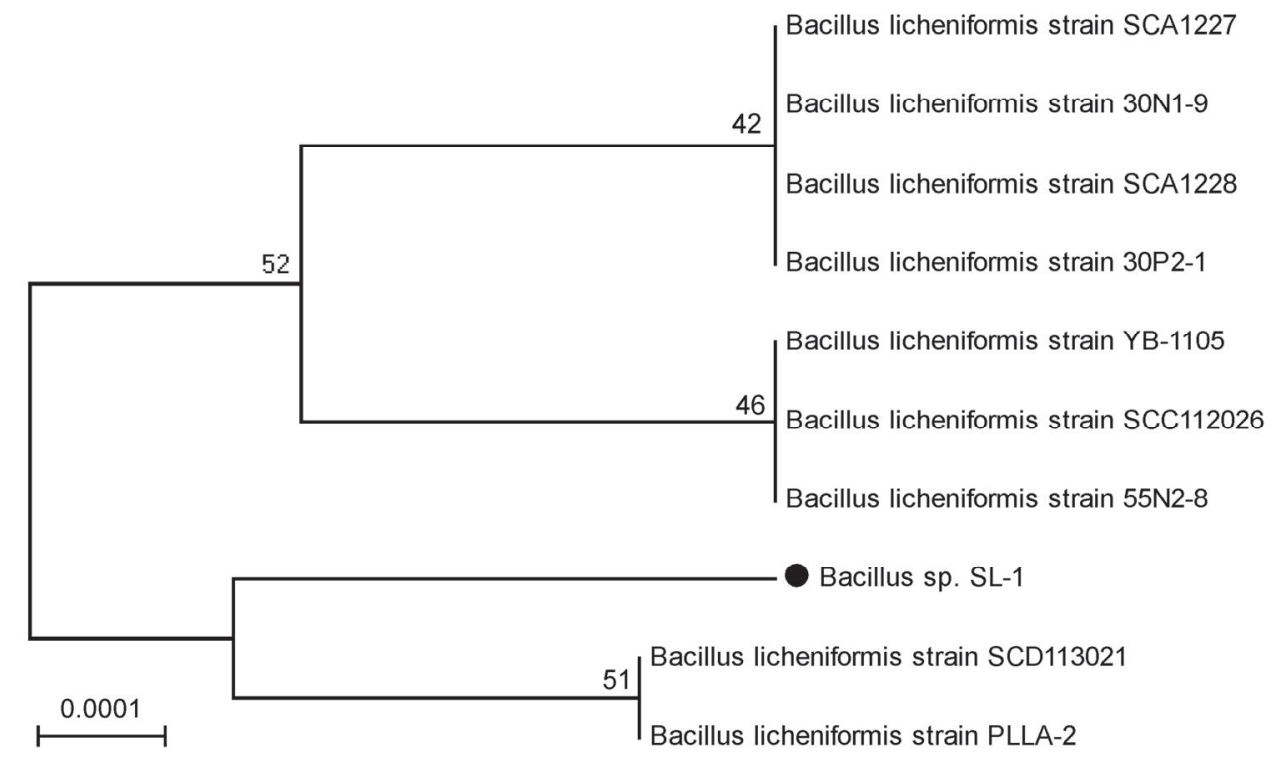

Fig. 1. Phylogenetic tree based on $16 \mathrm{~S}$ rDNA sequences, showing the relationship of the isolate SL1 to other members of the genus Bacillus.

Numbers at nodes are percentage bootstrap values based on 2,000 replications. Bar 0.0001 substitutions per nucleotide position

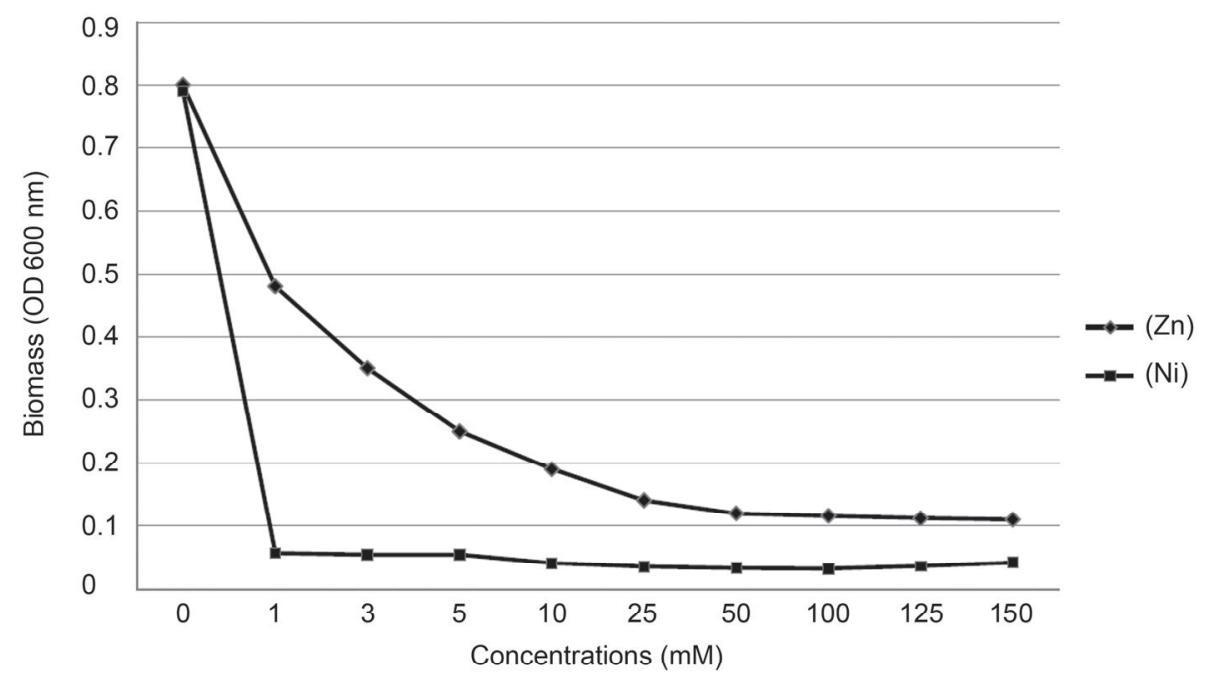

Fig. 2. Effects of different concentrations of zinc and nickel on growth of Bacillus sp. SL1

and plant material all over the world (Veith et al., 2004). Moreover, there are reports that this organism is olated from marine environments frequently (Ettoumi et al., 2009). But, to our knowledge, there is no report of B. licheniformis isolation from hypersalin Lakes, so far. Thus we tentatively named the SL1 isolate as Bacillus sp. SL1.

According to the results, SL1 isolate produced a strong biofilm in present of $10 \%$ and $20 \%$ sea salt. Also, this isolate exhibited tolerance to $1 \mathrm{mM}$ to $25 \mathrm{mM}$ concentration of zinc metal. A possible explanation for this ability is that SL1 isolate is protected in the environment conditions by using the biofilm formation. Based on previous investigations, the biofilm matrix has the potential to prevent diffusion of certain antimicrobial agents and heavy metal adsorption, thus restricting dispersion of compounds from the surrounding environment into the biofilm (Davey and Otoole, 2000; Maugeri etal., 2002; Tourney etal., 2009). Microbial biofilms contain bioorganic metal-complexing functional groups; thereby play an important function in metal cycling in contaminated environments. The results of Toner et al. (2005) study confirmed the importance of phosphoryl functional groups in zinc absorption by a bacterial biofilm. Also, there is a report of halophilic, thermotolerant B. licheniformis (B3-15), isolated from marine hot spring at Vulcano Island that was highly resistant to zinc (Maugeri et al., 2002). 
On the other hand, the growth of SL1 isolate was inhibited at very low concentration of nickel. In contrast of our study, Kamika and Momba (2011) found a B. licheniformis-ATTC12759 could tolerate nickel at concentrations ranging between 1 and $2 \mathrm{mM}$. These observations of Bacillus sp. SL1 are in disagreement with previous reports of B. licheniformis so far and mostly confirmed that these different probably could be to special properties of various strains of Bacillus isolated from unusual environment.

In this study, the Bacillus sp. SL1 evaluated as a good biosurfactant producer similar to $B$. licheniformis strains that isolated from diverse locations (Maugeri et al., 2002; Yakimov et al., 1995). These microorganisms and their compounds can be used to enhance oil recovery, clean oil storage tanks, increase flow though pipelines reduce the heavy oil viscosity and stabilize fuel wateroil emulsions (Safary et al., 2010). Thus probably this microorganism can play a significant role in the bioremediation and treatment of industrial wastewater.

In conclusion on the basis of results, the present study could represent a new halo-thermotolerant Bacillus for remarkable amylase, protease, DNase, biosurfactant and exopolysaccharides in order to usage in bioremediation, biocatalysts production, medical and pharmaceutical industrial.

\section{Acknowledgments}

This study was supported by the Anatomical Science Research Center, Kashan University of Medical Science (grant no. 9248)

\section{Literature}

Bagheri M., M. Didari, M.A. Amoozegar, P. Schumann, C. Ssnchez-Porro, M. Mehrshad and A. Ventosa. 2012. Bacillus iranensis sp. nov., a moderate halophile from a hypersaline lake. Int. J. Syst. Evol. Microbiol. 62: 811-816.

Bodour A.A., K.P. Drees and R.M. Maier. 2003. Distribution of biosurfactant-producing bacteria in undisturbed and contaminated arid southwestern soils. Appl. Environ. Microbiol. 69: 3280-3287.

Coronado M.C., C. Vargas, J. Hofemeister, A. Ventosa and J.J. Nieto. 2000. Production and biochemical characterization of an $\alpha$-amylase from the moderate halophile Halomonas meridian. Fems. Microbiol. Lett. 183: 67-71.

Davey M.E. and G.A. Otoole. 2000. Microbial biofilms: from ecology to molecular genetics. Microbiol. Mol. Biol. Rev. 64: 847-867.

Demergasso C., E.O. Casamayor, G. Chong, P. Galleguillos, L. Escudero and C. Pedros-Alio. 2004. Distribution of prokaryotic genetic diversity in athalassohaline lakes of the Atacama Desert, Northern Chile. FEMS. Microbiol. Ecol. 48: 57-69.

Ettoumi B., N. Raddadi, S. Borin, D. Daffonchio, A. Boudabous and A. Cherif. 2009. Diversity and phylogeny of culturable sporeforming Bacilli isolated from marine sediments. J. Basic. Microbiol. 49: 13-23.

Ghozlan H., H. Deif, R.A. Kandil and S. Sabry. 2006. Biodiversity of moderately halophilic bacteria in hypersaline habitats in Egypt. J. Gen. Appl. Microbiol. 52: 63-72.
Gomes J. and W. Steiner. 2004. The biocatalytic potential of extremophiles and extremozymes. Food Technol. Biotechnol. 42: 223-235.

Hassen A., N. Saidi, M. Cherif and A. Boudabous. 1998. Resistance of environmental bacteria to heavy metals. Bioresource. Technol. 64: 7-15.

Kamika I. and M.N. Momba. 2011. Comparing the tolerance limits of selected bacterial and protozoan species to nickel in wastewater systems. Sci. Total. Environ. 410-411: 172-181.

Lenore S.C., A.E. Greenberg and R.R. Trussell. 1989. Standard Methods for the Examination of Water and Wastewater, $17^{\text {nd }}$ ed. American Public Health Association, American Water Works Association, Water Pollution Control Federation, Washington, D.C.

Llamas I., J.A. Mata, R. Tallon, P. Bressollier, M.C. Urdaci, E. Quesada and V. Bejar. 2010. Characterization of the exopolysaccharide produced by Salipiger mucosus A3T, a halophilic species belonging to the Alphaproteobacteria, isolated on the Spanish Mediterranean Seaboard. Mar. Drugs. 8: 2240-2251.

Makhdoumi-Kakhki A., M.A. Amoozegar, B. Kazemi, L. Pasic and A. Ventosa. 2011. Prokaryotic diversity in Aran-Bidgol Salt Lake, the largest hypersaline playa in Iran. Microbes. Environ. 27: 87-93.

Margesin R. and F. Schinner. 2001. Potential of halotolerant and halophilic microorganisms for biotechnology. Extremophiles 5: 73-83.

Mata J.A., V. Bejar, I. Llamas, S. Arias, P. Bressollier, R. Tallon, M.C. Urdaci and E. Quesada. 2006. Exopolysaccharides produced by the recently described halophilic bacteria Halomonas ventosae and Halomonas anticariensis. Res. Microbiol. 157: 827-835.

Maugeri T.L., C. Gugliandolo, D. Caccamo, A. Panico, L. Lama, A. Gambacorta and B. Nicolaus. 2002. A halophilic thermotolerant Bacillus isolated from a marine hot spring able to produce a new exopolysaccharides. Biotechnol. Lett. 24: 515-519.

Morikawa, M., H. Daido, T. Takao, S. Murata, Y. Shimonishi, and T. Imanaka. 1993. A new Lipopeptide biosurfactant produced by Arthrobacter sp. strain MIS38. J. Bacteriol. 175: 6459-6466.

Nichols C.A.M., J. Guezennec and J.P. Bowman. 2005. Bacterial exopolysaccharides from extreme marine environments with special consideration of the Southern Ocean, Sea Ice, and Deep-Sea Hydrothermal Vents: a review. Mar. Biotechnol. 7: 253-271.

Oren A. 2002a. Diversity of halophilic microorganisms: Environments, phylogeny, physiology, and applications. J. Ind. Microbiol. Biotechnol. 28: 56-63.

Oren A. 2002b. Molecular ecology of extremely halophilic Archaea and Bacteria. Fems. Microbiol. Ecol. 39: 1-7.

Poli A., G. Anzelmo and B. Nicolaus. 2010. Bacterial exopolysaccharides from extreme marine habitats: production, characterization and biological activities. Mar. Drugs. 8: 1779-1802.

Rohban R., M.A. Amoozegar and A. Ventosa. 2009. Screening and isolation of halophilic bacteria producing extracellular hydrolyses from Howz Soltan Lake, Iran. J. Ind. Microbiol. Biotechnol. 6: 333-340.

Safary A., M. Roayayi Ardakani, A. Abolhasani Suraki, M. Akbarzade Khiavi and H. Motamedi. 2010. Isolation and Characterization of Biosurfactant Producing Bacteria from Caspian Sea. Biotechnology 9: 378-382.

Saitou N. and M. Nei. 1987. The neighbor-joining method: a new method for reconstructing phylogenetic trees. Mol. Biol. Evol. 4: 406-425.

Seno Y., R. Kariyama, R. Mitsuhata, K. Monden and H. Kumon. 2005. Clinical implications of biofilm formation by Enterococcus faecalis in the urinary tract. Acta. Med. Okayama. 59: 79-87.

Smibert R.M. and N.R. Krieg. 1994. Phenotypic characterization, pp. 607-654. In: Gerhardt P., R.G.E. Murray, W.A. Wood and N.R. Krieg (eds.), Methods for general and molecular bacteriology. American Society of Microbiology, Washington, D.C.

Tamura K., D. Peterson, N. Peterson, G. Stecher, M. Nei and S. Kumar. 2011. MEGA5: molecular evolutionary genetics analysis 
using maximum likelihood, evolutionary distance, and maximum parsimony methods. Mol. Biol. Evol. 28: 2731-2739.

Thompson J.D., D.G. Higgins and T.J. Gibson. 1994. CLUSTAL $\mathrm{W}$ : improving the sensitivity of progressive multiple sequence alignment through sequence weighting, position-specific gap penalties and weight matrix choice. Nucleic. Acids. Res. 22: 4673-4680.

Toner B., A. Manceau, M.A. Marcus, D.B. Millet and G. Sposito. 2005. Zinc sorption by a bacterial biofilm. Environ. Sci. Technol. 39: 8288-8294.

Tourney J., B.T. Ngwenya, J.W. Fred Mosselmans and M. Magennis. 2009. Physical and chemical effects of extracellular polymers (EPS) on Zn adsorption to Bacillus licheniformis S-86. J. Colloid. Interface. Sci. 337: 381-389.

Veith B., C. Herzberg, S. Steckel, J. Feesche, K.H. Maurer, P. Ehrenreich, S. Baumer, A. Henne, H. Liesegang, R. Merkl and others. 2004. The Complete genome sequence of Bacillus licheniformis DSM13, an organism with great industrial potential. J. Mol. Microbiol. Biotechnol. 7: 204-211.
Ventosa A., J. Nieto and A. Oren. 1998a. Biology of Moderately halophilic aerobic bacteria. Microbiol. Mol. Biol. Rev. 62: 504-544. Ventosa A., M.C. Marquez, M.J. Garabito and D.R. Arahal. 1998b. Moderately halophilic gram-positive bacterial diversity in hypersaline environment. Extremophiles 2: 297-304.

Weisburg W.G., S.M. Barns, D.A. Pelletier and D.J. Lane. 1991. $16 \mathrm{~S}$ ribosomal DNA amplification for phylogenetic study. J. Bacteriol. 173: 697-703.

Yakimov M.M., K.N. Timmis, V. Wray and H.L. Fredrickson. 1995. Characterization of a new lipopeptide surfactant produced by thermotolerant and halotolerant subsurface Bacillus licheniformis BAS50. Appl. Environ. Microbiol. 61: 1706-1713.

Yildiz E., B. OZCAN and M. Caliskan. 2011. Isolation, Characterization and Phylogenetic Analysis of Halophilic Archaea from a Salt Mine in Central Anatolia (Turkey). Pol. J. Microbiol 61: 111-117.

Zharkikh A. and W.H. Li. 1995. Estimation of confidence in phylogeny: the complete-and-partial bootstrap technique. Mol. Phylogenet. Evol. 4: 44-63.) 